\title{
Cost-Minimization Analysis of Linagliptin Compared to Sitagliptin in the Treatment of Type 2 Diabetes Mellitus from a Turkish Healthcare Perspective
}

Ergun Oksuz ${ }^{1}$, Simten Malhan ${ }^{2}$, Begum Urgancı $^{3}$ and Erkan Tetik $^{3}$

${ }^{1}$ Baskent University, Faculty of Medicine, Department of Family Medicine, Ankara, Turkey

${ }^{2}$ Baskent University, Faculty of Health Sciences, Ankara, Turkey

${ }^{3}$ Boehringer Ingelheim, Istanbul, Turkey

"Corresponding author: Dr Ergun Oksuz, MD, Professor, Baskent University, Faculty of Medicine, Department of Family Medicine, Ankara, Turkey, Tel: +903122466773; E-mail: eoksuz@baskent.edu.tr

Received date: April 21, 2017; Accepted date: May 03, 2017; Published date: May 10, 2017

Copyright: (c) 2017 Oksuz E, et al. This is an open-access article distributed under the terms of the Creative Commons Attribution License, which permits unrestricted use, distribution, and reproduction in any medium, provided the original author and source are credited.

\begin{abstract}
Objective: The aim of the present study is to evaluate linagliptin and sitagliptin in terms of pharmacoeconomics, by comparing the two dipeptidyl-peptidase 4 inhibitors (DPP-4i) with cost-minimization analysis.

Methods: Cost-minimization analysis was used to compare linagliptin and sitagliptin in terms of pharmacoeconomics. In a recent meta-analysis, linagliptin and sitagliptin were reported to have similar effects regarding the reduction in the $\mathrm{HbA} 1 \mathrm{c}$ levels achieved at the 24th week of treatment ( $\mathrm{HbA} 1 \mathrm{c}$ reduction at 24th week: $-0.8 \%$ ). Direct medical costs in Turkey were used for the comparisons. Cost data was constituted from the perspective of the healthcare payer, taking alternative therapies and all possible complications into consideration, and reviewing actual data from a tertiary healthcare center, related literature and clinical guidelines. A model was established with Microsoft Office Excel 2015 software, using the local data specifically from diabetes (DM) patients. Cost analysis was performed for one-year time frame.
\end{abstract}

Results: Average direct annual treatment cost per patient in type 2 diabetes mellitus (T2DM) was $€ 1,481.4$ with linagliptin and $€ 1,500.1$ with sitagliptin. In comparison to sitagliptin, linagliptin is determined to be a cost-saving alternative $(-€ 18.7)$. Probabilistic sensitivity analysis with Monte Carlo Simulation showed that linagliptin treatment (95\% confidence interval $€ 1,393.8-€ 1,523.9 ; n=1,000)$ is $52.9 \%$ equal or cost-saving compared to sitagliptin treatment $(95 \%$ confidence interval $€ 1,380.5-€ 1,509.1 ; n=1,000)$.

Conclusion: From the healthcare payer's perspective in Turkey regarding treatment of T2DM, linagliptin, a DPP-4 inhibitor, is a cost-saving treatment alternative to sitagliptin, with both having similar effects on HbA1c levels.

Keywords: Cost analysis; Diabetes mellitus; Dipeptidyl-peptidase 4 inhibitors; Linagliptin; Pharmacoeconomics; Sitagliptin

\section{Introduction}

Diabetes mellitus (DM) is a chronic disease with rapidly increasing prevalence as a pandemic on all over the world, and is an important cause of morbidity and mortality [1]. Type 2 diabetes mellitus (T2DM) is a chronic, multifactorial metabolic disorder characterized by insulin resistance in liver and peripheral tissues, accompanied by hyperglycemia due to relative insulin deficiency (T2DM). DM has a share of $12 \%$ of total health expenditures in the adult population, costing 650 billion dollars [2]. Various countries spend 3-12\% of their total health expenses to DM expenditures [3]. During the last two decades, DM prevalence has progressively increased in the European elderly population, because of the high prevalence of obesity and changing ethnicity [4]. DM prevalence is $8.8 \%$ for the entire world [2]. This rate has been reported as $8.9 \%$ in Germany, $8.1 \%$ in Spain, $6.4 \%$ in France, $6.1 \%$ in England, and $4.8 \%$ in Italy [4]. According to Ministry of Health records, it was $7.8 \%$ in Turkey by the year 2015 [5]. Because of the very high number of DM patients in Turkey, Turkey carries almost $13 \%$ of the diabetes burden in all Europe [2].
Annual total direct diabetes cost for five member states of European Union (EU) in 2010 was calculated as $€ 90$ billion, and indirect cost was calculated as $€ 98.4$ billion [4]. Per patient annual average diabetes cost was calculated as $€ 5,432$ in France, $€ 5,899$ in Germany, $€ 2,756$ in Italy, $€ 1,708$ in Spain, and $€ 4,744$ in England [6]. In 2010, diabetesrelated health expenses in Turkey were $\$ 6.5$ billion [7]. According to the Diab-Cost-2 study from Turkey, a study related to T2DM costs, per patient annual cost was an average $\$ 498$ for those who did not develop any complications; however, this number was determined to rise remarkably as the number of complications associated with DM increased. In the presence of related complications, cost of treatment and healthcare services may be 5 times greater than the cost of DM alone [8]. Therefore, it is important that appropriate treatments are initiated upon early diagnosis before complications develop.

In type $2 \mathrm{DM}$, pancreatic insulin release upon glucagon-like peptide (GLP-1) stimulation is insufficient, and the incretin hormones have reduced insulinotropic effect. Because, both incretin hormones which have peptide structure are degraded within minutes by the action of the enzyme dipeptidyl-peptidase-4 (DPP-4). DPP-4 is responsible for the degradation of many bioactive peptides in the body, such as GLP-1 and gastric inhibitor peptide (GIP). In order to regulate glucose levels, inhibitors of DPP-4 (DPP-4i), however, inhibit DPP-4 that inactivate 
incretin hormones released from the small intestines, and cause increased GLP-1 and GIP levels, and thereby, reduce levels of glucose and consequently HbA1c [9-11]. The (oral antidiabetic OAD) agents in the DPP-4i group, sitagliptin and linagliptin were included in the reimbursement list in Turkey, by the years 2008 and 2015, respectively. In comparison to other DPP-4i agents, linagliptin is the most potent inhibitor of DPP-4, and is the only DPP-4 inhibitor that is not eliminated through kidneys [12]. Linagliptin as a monotherapy has been found effective in achieving glycemic control in adult T2DM patients in studies with 12 and 24 weeks of study durations [13-16].

T2DM patients can develop renal complications, and this risk is especially higher in the elderly patients [17]. T2DM patients with renal complications have very limited treatment options. Because linagliptin is not excreted through the kidneys, it does not require dose adjustment in T2DM patients with renal disease [18-20]. Other DPP-4i agents require dose adjustment, therefore, linagliptin has advantages over other agent by not requiring dose adjustment in T2DM patients with renal disease [21-25].

In the present study, we evaluated the DPP- $4 \mathrm{i}$ agents linagliptin, an agent that is not primarly excreted through kidneys unlike the other ones, and sitagliptin, which has been included in the reimbursement list since 2008, in economical terms. As a means of economical evaluation, cost-minimization analysis was employed.

\section{Methodology}

Cost minimization analysis is a type of economical analysis to compare two healthcare technologies that are known or assumed to have similar outcomes. As a result of the analysis, the technology that is found to have less cost is accepted to have higher efficiency [26]. In cost minimization analysis, sitagliptin was chosen as the comparator. The reason why linagliptin was compared to sitagliptin is that there are no studies on other DPP-4 inhibitor agents that yielded the same level of effectiveness and spanned the same length of treatment period. In one meta-analysis including 15 clinical studies on sitagliptin and 10 studies on linagliptin, which involved totally 11234 patients, both linagliptin and sitagliptin were found to have the same level of effectiveness in regarding reduction in HbAlc levels, which is an indicator of glycemic control (HbA1c response achieved at the 24th week of treatment: -0.8\%) [27]. The costs of both treatment modalities were calculated from the perspective of the healthcare payer. Only the direct medical costs were taken into consideration, and other indirect or intangible costs were not included in the analysis. Initially, annual costs were calculated, and consequently, treatment costs for a period of 24 weeks were compared against each other. In order to calculate treatment cost with each treatment modalities, clinical guidelines and local epidemiological literature were accounted; and for calculation of costs associated with complications, actual data from a tertiary healthcare center was used [28-49].

The national healthcare payer in Turkey, the Social Security Institution issues a reimbursement list called the Health Application Rescript. All reimbursements are executed by the healthcare payer according to this list, following regulations regarding the provided healthcare services. Cost of the medications was calculated according to the Republic of Turkey Ministry of Health Turkish Medicines and Medical Devices Agency (TMMDA) 2015 list. The drugs were classified according to the active ingredients and all forms of all products included in the reimbursement list related to the active ingredients and were included in the analysis, and their average values were reflected to the calculations. The analyses were performed based on Health Application Rescript issued on 21st April 2015, and drugs' public costs by 4th June 2015; all costs were converted to Euro currency ( $1 €=3,05 €$, TR Central Bank, 4th June 2015).

The study was conducted with two groups, and amount of healthcare utilization, the proportion of patients who make use of the healthcare service, and unit costs were bunched together. For unit costs, the reimbursement prize determined by the healthcare payer was taken into account. For pharmacotherapy, again the prize determined by the healthcare payer was taken into account.

\section{Statistical analyses}

The study was conducted with a deterministic model developed by Microsoft $^{\oplus}$ Excel $^{\oplus}$ 2015. A sensitivity analysis was performed to test whether and how changing any of the assumptions affected the overall results. Uncertainties in the model were tested using the $95 \%$ confidence intervals and standard deviation tests.

\section{Results}

\section{Cost results}

\begin{tabular}{|c|c|c|c|}
\hline Outpatient & $\%$ & \# of visit & Unit cost $(€)$ \\
\hline Endocrinology & 10.6 & 6 & 9.3 \\
\hline Internal Medicine & 71.1 & 6 & 9.6 \\
\hline Family Physician & 18.3 & 6 & 6.3 \\
\hline Ophthalmology & 100 & 2 & 8.1 \\
\hline Cardiology & 100 & 2 & 11.8 \\
\hline Emergency Service & 24.3 & 1 & $28.7^{*}$ \\
\hline Nephrology & 22.5 & 1 & 10.2 \\
\hline Laboratory Tests & $\%$ cases & \# of test & Unit cost $(€)$ \\
\hline Glucose & 100 & 6 & $0.3^{* *}$ \\
\hline Lipid profile & 100 & 2 & $1.7^{* *}$ \\
\hline $\mathrm{HbA} 1 \mathrm{c}$ & 100 & 4 & 1.3 \\
\hline Renal function tests & 100 & 2 & $2.1^{\star *}$ \\
\hline Microalbuminuria & 100 & 2 & $1.9^{* *}$ \\
\hline Urinalysis & 100 & 2 & $0.4^{* *}$ \\
\hline ECG & 100 & 2 & $1.0^{* *}$ \\
\hline Liver function tests & 100 & 2 & $1.4^{\star *}$ \\
\hline Thyroid function tests & 39 & 1 & $4.4^{* *}$ \\
\hline
\end{tabular}

Table 1: Distribution of visited outpatient clinics and laboratory test performed, and unit costs. 
Citation: Oksuz E, Malhan S, Urganci B, Tetik T (2017) Cost-Minimization Analysis of Linagliptin Compared to Sitagliptin in the Treatment of Type 2 Diabetes Mellitus from a Turkish Healthcare Perspective. J Diabetes Metab 8: 739. doi:10.4172/2155-6156.1000739

Page 3 of 6

During T2DM treatment, the distribution of the outpatient clinics visited by patients and the complications they suffer may vary, resulting in different sorts of costs. We calculated the cost of outpatient clinic visits based on the reports by the ADMIRE study from Turkey by Satman et al. [49], which reported the distribution of outpatient clinic visits by T2DM patients within a year (Table 1). The difference between the two treatment modalities with regard to outpatient clinic visits is caused by difference in the nephrology outpatient clinic services. Linagliptin does not require dose adjustment in T2DM patients with renal impairment [18-25]. Average annual per-patient outpatient clinic visit cost is calculated as $€ 96,7$ with linagliptin and $€$ 99,0 with sitagliptin. Additionally, since the cost of most of the laboratory and imaging examinations during outpatient clinic visits are included in the package prize according to the reimbursement regulations in Turkey, no additional cost was reflected for most of the tests. Table 2 shows the distribution of laboratory tests that are performed on DM patients during diagnostic workup and treatment follow-up. The tests are the routine laboratory tests that are recommended by the diagnosis and treatment guidelines as part of the routine practice, and the number of repeated tests within a year was obtained from the literature [50].

\begin{tabular}{|l|l|l|l|l|l|}
\hline $\begin{array}{l}\text { Dipeptidyl } \\
\text { peptidase-4 } \\
\text { inhibitor }\end{array}$ & $\begin{array}{l}\text { Cost per } \\
\text { pack }\end{array}$ & $\begin{array}{l}\text { Number of } \\
\text { tablet per } \\
\text { pack }\end{array}$ & $\begin{array}{l}\text { Dose per } \\
\text { tablet }\end{array}$ & Posology & $\begin{array}{l}\text { Daily } \\
\text { Drug } \\
\text { cost }\end{array}$ \\
\hline Linagliptin & $€ 18.02$ & 30 & $5 \mathrm{mg}$ & Once daily & $€ 0.6$ \\
\hline Sitagliptin & $€ 17.34$ & 28 & $100 \mathrm{mg}$ & Once daily & $€ 0.62$ \\
\hline
\end{tabular}

Table 2: Drug acquisition costs used in the economic evaluation.

\begin{tabular}{|c|c|c|c|}
\hline \multirow[b]{2}{*}{ Medications } & \multirow[b]{2}{*}{$\%$ patient } & \multicolumn{2}{|c|}{ Unit cost $(€)^{* *}$} \\
\hline & & Linagliptin & Sitagliptin \\
\hline OAD single therapy & 54.7 & 216.3 & 225.4 \\
\hline OAD double and triple therapy & 29.4 & 307.7 & 316.8 \\
\hline Insulin therapy & 3 & 456.3 & 456.3 \\
\hline OAD and insulin therapy & 12.9 & 672.6 & 681.7 \\
\hline Influenza vaccine & 100 & 3.9 & 3.9 \\
\hline Pneumococcus vaccine* & 100 & - & - \\
\hline $\begin{array}{l}\text { Daily blood glucose monitoring at } \\
\text { home }\end{array}$ & 4.4 & 85 & 85 \\
\hline
\end{tabular}

*Administered by TR Ministry of Health without any charges. ${ }^{* *}$ Calculated as average annual value on the assumption that treatment compliance is $100 \%$ for all patients.

Table 3: Distribution of medications in treatment of T2DM.

Distribution of treatment options for T2DM in the study population is as follows: single OAD in $54.7 \%$; double and triple OAD in $29.4 \%$; insulin in $3.0 \%$; OAD and insulin in $12.9 \%$ of patients. Vaccines for influenza and pneumococcus are employed in $100 \%$ of the patients, and apart from the ones administering insulin injections, totally $4.4 \%$ of patients regularly monitor their blood glucose once a day at home $[51,52]$. In both groups of the study, the treatments were administered as either monotherapy or as part of the combination therapy (Tables 2 and 3). A pack of linagliptin preparation contains 30 tablets, and the posology calculations were based on DDD, and on the assumption that 12 packs are used in year. A pack of sitagliptin preparation contains 28 tablets, therefore 13 packs are assumed to be used per year. Although their posology is the same, their costs differ because of the number of tablets included in a given pack (Table 2). Average annual per-patient medication cost in T2DM treatment with linagliptin was calculated as $€ 316.9$; and average annual per-patient medication cost with sitagliptin was $€ 325.7$.

As chronic complications of T2DM, $22.5 \%$ of patients have renal impairment, $25.4 \%$ have retinopathy, $41.1 \%$ have neuropathy, $6.7 \%$ have stroke, $28.9 \%$ have coronary artery disease and $6.2 \%$ have peripheral artery disease; and annually $6.2 \%$ of patients experience hypoglycemia [51]. Annual costs associated with the related complications were calculated from the actual data coming from a tertiary healthcare center. Table 4 presents distributions of complications and costs associated with them.

\begin{tabular}{|l|l|l|}
\hline Complications & Frequency \% & $\begin{array}{l}\text { Annual cost } \\
\text { (Euro) }\end{array}$ \\
\hline Renal impairment & 22.5 & 2146 \\
\hline Retinopathy & 25.4 & 165.7 \\
\hline Neuropathy & 41.1 & 618.4 \\
\hline Stroke & 6.7 & 812.2 \\
\hline Cononary artery disease & 28.9 & 587.7 \\
\hline Peripheral artery disease & 6.2 & 386.6 \\
\hline Hypoglycemia & 6.2 & 40.1 \\
\hline Diabetic coma & 1.3 & 229.2 \\
\hline
\end{tabular}

Table 4: Complications of type 2 diabetes and their average costs.

Costs of the complications were weighted according to their prevalence, and as a result, average annual per-patient cost was calculated as $€ 1029.8$. The cost was reflected evenly to both treatment groups.

As a result, treatment of T2DM with linagliptin yielded average annual per-patient cost of outpatient clinic visit and associated tests as $€$ 105.7, average annual per-patient cost of hospitalization and interventions as $€ 29.0$, average annual per-patient cost of medications as $€ 316.9$, and average cost of diabetic complications as $€ 1,029.8$. Accordingly, average annual per-patient cost with linagliptin was determined as $€ 1,481.4$ (Table 5).

On the other hand, treatment of T2DM with sitagliptin yielded average annual per-patient cost of outpatient clinic visit and associated tests as $€ 115,6$, average annual per-patient cost of hospitalization and interventions as $€ 29,0$, average annual per-patient cost of medications as $€ 325,7$, and average cost of diabetic complications as $€ 1,029,8$. Accordingly, average annual per-patient cost with sitagliptin was determined as $€ 1,500,1$ (Table 5).

According to the results of the analysis, hospitalization and intervention costs had a share of $2 \%$, and outpatient clinic visits and associated laboratory tests had a share of $7 \%$ in the total annual cost of T2DM disease, whereas medication costs had a share of $22 \%$ in the total cost. The major share of the cost of T2DM disease was made by costs associated with diabetic complications. 


\begin{tabular}{|l|l|l|}
\hline Cost components & With linagliptin $(€)$ & With sitagliptin $(€)$ \\
\hline $\begin{array}{l}\text { Cost of outpatient clinic visits } \\
\text { and associated tests }\end{array}$ & 105.7 & 115.6 \\
\hline $\begin{array}{l}\text { Cost of hospitalizations and } \\
\text { interventions }\end{array}$ & 29 & 29 \\
\hline Cost of medications & 316.9 & 325.7 \\
\hline $\begin{array}{l}\text { Costs associated with } \\
\text { complications }\end{array}$ & 1029.8 & 1029.8 \\
\hline Total & 1481.4 & 1500.1 \\
\hline
\end{tabular}

Table 5: Average annual per-patient costs of type 2 diabetes treatment with linagliptin and sitagliptin.

\section{Sensitivity analysis}

During diagnosis and treatment phases of T2DM disease, various services provided by outpatient clinics, hospitals and laboratory units are used along with many pharmacological agents and medical equipments, and there is also the burden of the costs of the chronic complications associated with the disease. To assess the distribution and accuracy of the results, calculations were made separately for each variable. Thus, results of each variable were represented by the probabilities that were calculated specifically for the given variable. As a result of the sensitivity analysis (Table 6), the standard deviation values were determined as $€ 1049.2$ for treatment with linagliptin $(\mathrm{n}=1.000,95 \%$ confidence interval $€ 1393.8-1523.9)$ and $€ 1037.2$ ( $\mathrm{n}=1.000, \% 95$ confidence interval $€ 1380.5-1509.1$ ) for treatment with sitagliptin. According to the analysis, linagliptin treatment was found to equal or cost-saving in $52.9 \%$ of the cases compared to sitagliptin treatment.

\begin{tabular}{|l|l|l|}
\hline & Linagliptin & Sitagliptin \\
\hline $\mathrm{N}$ & 1000 & 1000 \\
\hline Standard deviation $(€)$ & 1049.2 & 1037.3 \\
\hline$\% 95$ confidence interval $(€)$ & $1393.8-1523.9$ & $1380.5-1509.1$ \\
\hline Minimum - maximum $(€)$ & $49.0-4924.4$ & $59.2-4928.5$ \\
\hline
\end{tabular}

Table 6: Results of probabilistic sensitivity analysis for total costs of treatment with linagliptin and sitagliptin in type 2 diabetes.

\section{Conclusion}

Linagliptin is a selective competitive DPP- $4 \mathrm{i}[12,53,54]$ used in the treatment of T2DM in many countries including US [18] and EU [19]. Compared to other DPP-4i agents, linagliptin is the most potent inhibitor of the enzyme DPP-4, and is the only DPP-4i that is not primarily eliminated through kidneys [12]. In addition, it is administered once a day, which helps to enhance the compliance with the treatment.

Every $1 \%$ reduction of $\mathrm{HbA} 1 \mathrm{c}$ level in $\mathrm{T} 2 \mathrm{DM}$ can reduce mortality due to DM by $25 \%$ and mortality due to all causes by $7 \%$. Furthermore, every $1 \%$ reduction in $\mathrm{HbA} 1 \mathrm{c}$ levels reduces AMI prevalence by $18 \%$, and risks of CHF development by $16 \%$, lower extremity amputations by $43 \%$, stroke development by $12 \%$ and microvascular complications by $35 \%[35,36]$. In the presence of complications, costs of treatment and healthcare services in DM may exceed 5 times of the cost of the DM treatment alone [8]. Therefore, controlling HbA1c levels in DM patients is of utmost importance in terms of reducing the immaterial costs to the patient and the economic burden on the whole population. A $0.8 \%$ reduction in $\mathrm{HbAlc}$ level can be achieved at the end of the 24th week of treatment with either linagliptin or sitagliptin [27].

Considering the increasing number of patients with DM, prompt diagnosis and initiation of proper treatment are important in order to ease the growing economic burden. Limited resources, growing population and expectations have led to discovery of new treatment modalities, and these new treatments were introduced to the market with higher prize.

When performing economical evaluation of new healthcare technologies that are subject to reimbursement, there is a vacancy for economical evaluation of the healthcare technologies that were introduced to the reimbursement list earlier. However, introduction of new and clinically superior healthcare technologies to the market necessitates re-evaluation of the previous healthcare technologies. Thus, these technologies can be reassessed to allow more efficient use the national resources. For this reason, retrospective economical evaluation of the healthcare technologies is recommended. These evaluations are expected to yield evidence based data to aid policy makers in efficient distribution of the resources.

Limitations of this cost-minimization analysis include assumptions of $100 \%$ compliance and clinical equivalence in terms of adverse events (AEs). Both DPP4i's are available in tablet form and are orally administered once daily, and are therefore theoretically subject to the same level of treatment compliance.

\section{Disclosure}

Ergun Oksuz and Simten Malhan are employees of Baskent University that conducted the analysis; Begum Urganci and Erkan Tetik are employees of Boehringer Ingelheim.

\section{Acknowledgements}

This research was funded by Boehringer Ingelheim, Istanbul-Turkey.

\section{References}

1. Ashcroft FM, Rorsman P (2012) Diabetes mellitus and the $\beta$ cell: the last ten years. Cell 148: 1160-1171.

2. International Diabetes Federation (2015) IDF Diabetes Atlas 7th Edition revision Brussels, Belgium 1:16-17.

3. Donovan DS (2002) Epidemiology of diabetes and its burden in the World and in the United States. In: Poretsky L (editor) Principles of Diabetes Mellitus. Kluwer Academic Publishers, Boston, Dordrecht, London 2: 107-121.

4. Kanavos P, van den Aardweg S, Schurer W (2012) Diabetes expenditure, burden of disease and management in 5 EU countries. LSE Health, London School of Economics. London UK 3: 21-33

5. Republic of Turkey, Ministry of Health (2016) 2015 Health-Net Data. Ankara Turkey.

6. International Diabetes Federation (2006) IDF Diabetes Atlas (3rdedn) Brussels, Belgium.

7. Infernational Diabetes Leaders' Summit (2013) The issue of diabetes in Turkey and in countries in the region. Istanbul, Turkey.

8. Akalin S, Satman I, Ozdemir O, Turkish DM-COST Study Group (2012) Cost of disease and its relationship with diabetic complications in Turkish 
patients with type 2 diabetes mellitus. ISPOR 15th Annual European Congress. Value in Health 15: 498.

9. Miller S, St Onge EL (2006) Sitagliptin: a dipeptidyl peptidase IV inhibitor for the treatment of type 2 diabetes. Ann Pharmacother. 40 : 1336-43.

10. Zhong J, Gong Q, Goud A, Srinivasamaharaj S, Rajagopalan S (2015) Recent Advances in Dipeptidyl-Peptidase-4 Inhibition Therapy: Lessons from the Bench and Clinical Trials. J Diabetes Res 2015: 606031.

11. Green BD, Flatt PR, Bailey CJ (2006) Dipeptidyl peptidase IV (DPP IV) inhibitors: A newly emerging drug class for the treatment of type 2 diabetes. Diab Vasc Dis Res 3: 159-165.

12. Deeks ED (2012) Linagliptin: a review of its use in the management of type 2 diabetes mellitus. Drugs 72: 1793-1824.

13. Del Prato S, Barnett AH, Huisman H, Neubacher D, Woerle HJ, et al. (2011) Effect of linagliptin monotherapy on glycaemic control and markers of $\beta$-cell function in patients with inadequately controlled type 2 diabetes: a randomized controlled trial. Diabetes Obes Metab 13. 258-267.

14. Kawamori R, Inagaki N, Araki E, Watada H, Hayashi N, et al. (2012) Linagliptin monotherapy provides superior glycaemic control versus placebo or voglibose with comparable safety in Japanese patients with type 2 diabetes: a randomized, placebo and active comparator-controlled, double-blind study. Diabetes Obes Metab 14: 348-357.

15. Barnett AH, Harper R, Toorawa R, Patel S, Woerle HJ (2010) Linagliptin monotherapy improves glycaemic control in type 2 diabetes patients for whom metformin therapy is inappropriate. Diabetologia 53: S327.

16. Patel S, Barnett AH, Harper R (2011) 1 yr linagliptin monotherapy is well tolerated \& sustains improvement in glycaemic control in patients for whom metformin is inappropriate. Proceedings of the International Diabetes Federation World Diabetes Congress.

17. National Kidney Foundation. Diabetes and chronic kidney disease.

18. Boehringer Ingelheim International $\mathrm{GmbH}$. Tradjenta (linagliptin) tablets: US prescribing information.

19. Boehringer Ingelheim International $\mathrm{GmbH}$. Trajenta $5 \mathrm{mg}$ film-coated tablets; summary of product characteristics.

20. Boehringer Ingelheim International $\mathrm{GmbH}$. Tradjenta (linagliptin) tablets: US prescribing information.

21. Merck Sharp \& Dohme Corp. Januvia (sitagliptin) tablets: US prescribing information.

22. Merck Sharp \& Dohme Ltd. Januvia film-coated tablets: summary of product characteristics.

23. Novartis Pharma GmbH. Galvus tablets: summary of product characteristics.

24. Bristol-Myers Squibb and AstraZeneca EEIG. Onglyza film-coated tablets: summary of product characteristics.

25. Bristol-Myers Squibb Company and AstraZeneca Pharmaceuticals LP. Onglyza (saxagliptin) tablets: US prescribing information.

26. Oksuz E, Malhan S (2005) Health related Quality of Life-Qualimetri. Baskent University Ankara Turkey 11: 140-174.

27. Gross JL, Rogers J, Polhamus D, Gillespie W, Friedrich C, et al. (2013) A novel model-based meta-analysis to indirectly estimate the comparative efficacy of two medications: an example using DPP-4 inhibitors, sitagliptin and linagliptin, in treatment of type 2 diabetes mellitus. BMJ Open 3: 001844.

28. Diabetes Mellitus Study and Education Group (2016) Turkish Endocrinology and Metabolism Association. Guideline on diagnosis, treatment and follow-up of diabetes mellitus and its complications. (8thedn). Ankara, Turkey.

29. Ozata M (2011) Diabetes Mellitus. Endocrinology Metabolism and Diabetes. (2ndedn) İstanbul Medicine Bookstore Publishing, İstanbul Turkey.

30. Sercer E (2001) Diabetes Mellitus, Endocrinology, Metabolism and Nutritional Diseases. Nobel Bookstore Ankara Turkey.

31. Unger J (2007) Management of type 1 diabetes. Prim Care 34: 791-808.
32. Eisenbarth GS (2004) Type 1 Diabetes Mellitus. In: Kahn CR, Weir GC, (editors) Joslin's Diabetes Mellitus. (14thedn). LWW Boston MA.

33. Melmed S, Polonsky KS, Larsen PR, Krononberg HM (2011) Williams Textbook of Endocrinology (12thedn) Philadelphia Saunders Elsevier.

34. Gardner D, Shoback D (2011) Greenspan's Basic and Clinical Endocrinology, (9thedn) LANGE Clinical Medicine McGraw-Hill Medical.

35. UK Prospective Diabetes Study (UKPDS) Group (1998) Intensive bloodglucose control with sulphonylureas or insulin compared with conventional treatment and risk of complications in patients with type 2 diabetes (UKPDS 33). Lancet 352: 837-853.

36. UK Prospective Diabetes Study (UKPDS) Group (1999) Glycemic control with diet, sulfonylurea, metformin, or insulin in patients with type 2 diabetes mellitus: progressive requirement for multiple therapies (UKPDS 49). JAMA 281:2005-2012.

37. European Diabetes Policy Group (1999) A desktop guide to Type 2 diabetes mellitus. Diabet Med 16: 716-730.

38. The Diabetes Control and Complications Trial Research Group (1993) The effect of intensive treatment of diabetes on the development and progression of long-term complications in insulin-dependent diabetes mellitus. N Engl J Med 329: 977-986.

39. Temelkova-Kurktschiev TS, Koehler C, Henkel E, Leonhardt W, Fuecker $\mathrm{K}$, et al. (2000) Postchallenge plasma glucose and glycemic spikes are more strongly associated with atherosclerosis than fasting glucose or HbAlc level. Diabetes Care 23: 1830-1834.

40. Seino S, Takahashi H, Takahashi T, Shibasaki T (2012) Treating diabetes today: a matter of selectivity of sulphonylureas. Diabetes Obes Metab 14: 9-13.

41. Goldberg RB, Holvey SM, Schneider J (1996) A dose-response study of glimepiride in patients with NIDDM who have previously received sulfonylurea agents. The Glimepiride Protocol \#201 Study Group. Diabetes Care 19: 849-856

42. Simonson DC, Kourides IA, Feinglos M, Shamoon H, Fischette CT (1997) Efficacy, safety, and dose-response characteristics of glipizide gastrointestinal therapeutic system on glycemic control and insulin secretion in NIDDM. Results of two multicenter, randomized, placebocontrolled clinical trials. Diabetes Care 20: 597-606.

43. Inzucchi SE (2002) Oral antihyperglycemic therapy for type 2 diabetes: scientific review. JAMA 287: 360-372.

44. Mizuno CS, Chittiboyina AG, Kurtz TW, Pershadsingh HA, Avery MA (2008) Type 2 diabetes and oral antihyperglycemic drugs. Curr Med Chem 15: 61-74.

45. Cheng AY, Fantus IG (2005) Oral antihyperglycemic therapy for type 2 diabetes mellitus. CMAJ 172: 213-226.

46. Krentz AJ, Bailey CJ (2005) Oral antidiabetic agents: current role in type 2 diabetes mellitus. Drugs 65: 385-411.

47. Rendell M (2004) The role of sulphonylureas in the management of type 2 diabetes mellitus. Drugs 64: 1339-1358.

48. Levetan C (2007) Oral antidiabetic agents in type 2 diabetes. Curr Med Res Opin 23: 945-952.

49. Satman I, Imamoglu S, Yilmaz C, ADMIRE Study Group (2012) A patient-based study on the adherence of physicians to guidelines for the management of type 2 diabetes in Turkey. Diabetes Res Clin Pract 98: 75-82.

50. Athanasakis K, Ollandezos M, Angeli A, Gregoriou A, Geitona M, et al. (2010) Estimating the direct cost of Type 2 diabetes in Greece: the effects of blood glucose regulation on patient cost. Diabet Med 27: 679-684.

51. Gur S (2013) Canakkale Province's Type1 and Type2 Diabetes Diseases Report, Dissertation, Onsekiz Mart University, Canakkale Turkey.

52. Satman I, Omer B, Tutuncu Y, Kalaca S, Gedik S, et al. (2013) Twelve-year trends in the prevalence and risk factors of diabetes and prediabetes in Turkish adults. Eur J Epidemiol 28: 169-180.

53. Forst T, Pfützner A (2012) Linagliptin, a dipeptidyl peptidase-4 inhibitor with a unique pharmacological profile, and efficacy in a broad range of patients with type 2 diabetes. Expert Opin Pharmacother 13: 101-110. 
Citation: Oksuz E, Malhan S, Urganci B, Tetik T (2017) Cost-Minimization Analysis of Linagliptin Compared to Sitagliptin in the Treatment of Type 2 Diabetes Mellitus from a Turkish Healthcare Perspective. J Diabetes Metab 8: 739. doi:10.4172/2155-6156.1000739

Page 6 of 6

54. McGill JB (2012) Linagliptin for type 2 diabetes mellitus: a review of the pivotal clinical trials. Ther Adv Endocrinol Metab 3: 113-124. 